\title{
Steel Building Friction Connection Seismic Performance - Corrosion Effects
}

\author{
Jose Christian Chanchi Golondrino ${ }^{\mathrm{a}, \mathrm{b}, 1^{*}}$, Gregory Anthony MacRae ${ }^{\mathrm{b}, 2}$, James Geoffrey \\ Chase $^{\mathrm{c}, 3}$, Geoffrey William Rodgers ${ }^{\mathrm{c}, 4}$, Allan Charles Nye Scott ${ }^{\mathrm{b}, 5}$, \\ George Charles Clifton ${ }^{\mathrm{d}, 6}$ \\ ${ }^{a}$ Universidad Nacional de Colombia, Departamento de Ingeniería Civil, Manizales - \\ Caldas 170004, Colombia. \\ ${ }^{\mathrm{b}}$ University of Canterbury, Department of Civil and Natural Resources Engineering, \\ Private Bag 4800, Christchurch 8140, New Zealand. \\ ${ }^{c}$ University of Canterbury, Department of Mechanical Engineering, Private Bag 4800, \\ Christchurch 8140, New Zealand. \\ d The University of Auckland, Department of Civil \& Environmental Engineering, Faculty \\ of Engineering, Private Bag 92019, Auckland Mail Centre, Auckland 1142, New Zealand. \\ 1 jcchanchigo@unal.edu.co, ${ }^{2}$ gregory.macrae@ canterbury.ac.nz, \\ ${ }^{3}$ geoff.chase@ canterbury.ac.nz, ${ }^{4}$ geoff.rodgers@ canterbury.ac.nz, \\ 5allan.scott@canterbury.ac.nz, ${ }^{6}$ c.clifton@ auckland.ac.nz \\ ${ }^{*}$ Corresponding author
}

\section{"Declarations of interest: none"}

Key words: Steel building connection, Friction connections, Low damage dissipaters, Corrosion, Surface treatment.

\section{ABSTRACT}

Asymmetric Friction Connections (AFCs) dissipate energy in structural systems. Surface treatments and severe corrosion effects on AFC strength, and the corrosion mechanism of AFCs have not been explained yet. A total of 12 AFCs were surface treated, exposed to a severe corrosive regime, and cyclically loaded. Surface treatments, such as cleaned, sweep blasted, alkyd coated, and zinc coated surfaces were considered. AFC strength and the stability of the hysteresis loop of the connection were sensitive to both surface treatment and corrosion. AFCs developed general, crevice, and filiform corrosion not only at the external ${ }^{1}$ AFC: Asymmetric Friction Connection 
surfaces, but also at the internal clamped surfaces for some surface treatments. As a result of corrosion, connection strength increased at the initial sliding cycles up to $100 \%, 120 \%$, $130 \%$, and $50 \%$ for cleaned, sweep blasted, alkyd coated, and zinc coated surfaces, respectively. After the corrosive product is removed by the sliding of the slotted plate, the connection strength returned to approximately the strength of the non-corroded connections. These results were used to propose a model to predict the maximum and minimum likely AFC strengths when plate surfaces of the plates are treated, and when these four surface treatments are severely corroded. The experimental results, and resulting model, provide significant insight and design tools for the practical use of AFCs in design.

\section{INTRODUCTION}

AFCs are friction bolted connections used to dissipate seismic energy. AFCs can be assembled using three Grade 300 steel plates, two thin plates termed shims made of high hardness materials, such as Bisalloy 400 or Bisalloy 500, and high strength structural bolts, such as Grade 8.8 bolts. AFCs dissipate energy via friction when a slotted plate is forced to slide over the shims $[1,2,3]$. The sliding force of the resulting approximately square hysteresis loop is termed the AFC strength, and quasi-static testing has shown it may be almost constant [1].

AFCs were initially proposed using brass shims [2]. Results showed dissimilar sliding surfaces may develop predictable stable hysteretic behaviour. The effect of dissimilar sliding surfaces on the AFC hysteresis loop stability was experimentally validated when testing AFCs with slotted plates of Grade 300 steel and shims with nominal Brinell hardness varying between $130 \mathrm{BH}-400 \mathrm{BH}[1]$. Results showed increasing the shims hardness increased the 
hysteresis loop stability and predictability of AFC strength. Given the benefits of high hardness shims on the AFC hysteresis loop stability, the use of Bisalloy 500 shims (Brinell hardness of 500BH) in AFCs with slotted plates of Grade 300 steel were introduced [3]. Testing of these AFCs showed repeatable and very stable hysteretic performance with low degradation on the sliding surfaces.

Applications of AFCs as seismic dissipaters in structural systems non-exposed to corrosive environments have been also experimentally validated $[2,4,5,6,7]$. These studies considered dissipation of AFCs at beam column joints [2, 4], at column bases [5, 6], and within braces [7]. Results showed:

i. Structural systems equipped with AFCs had stable and predictable hysteretic response,

ii. AFCs can successfully protect structural systems from yielding or damage when the structural system undergo large drifts, and

iii. Low damage was observed on the AFCs sling interfaces, and yielding on AFCs bolts, which both may easily be replaced.

Applications of AFCs have been restricted to structural systems located in interior environments or environments where atmospheric conditions will not corrode AFC components, or AFCs without surface treatment on the sliding interfaces [2]. In particular, there is no robust experimental data describing the effect of severe corrosion on the hysteretic behaviour of AFCs. There are also no experimental studies examining how AFC surface treatments under severe corrosion modifies AFC hysteretic behaviour. Some evidence that 
surface treatments and corrosion compromise the performance of AFCs is based on the reduction in hysteresis loop stability and strength observed in AFCs with treated surfaces and cyclically tested after a preliminary corrosion testing [3]. However, the AFCs in this study were not severely corroded. There is a need to understand and characterize this behaviour. To address these needs, this paper seeks answers to following questions:

i. What types of corrosion develop in AFCs with different surface treatments under a severe corrosive regime?

ii. What is the corrosion mechanism of AFCs with different surface treatments, and what is the most efficient surface treatment to protect AFCs under a severe corrosive regime?

iii. What are the effects of different surface treatments on the hysteretic behaviour of AFCs?

iv. What are the effects of a severe corrosion regime on the hysteretic behaviour of AFCs with different surface treatments?

v. What are the effects of surface treatments and severe corrosion on the effective friction coefficient of AFCs?

vi. Is there a simple model to assess AFC strength considering the effects of different surface treatments and corrosion? 


\section{MATERIALS AND METHODS}

\subsection{AFC dimensions}

Two types of AFC specimens were assembled: AFCs joints and full scale AFCs. AFC joints were used for describing the effects of corrosion on bolts and sliding surfaces after AFC joints were subjected to accelerated corrosion conditions. Full scale AFCs were used for assessing the hysteretic behaviour after full scale AFCs were subjected to accelerated corrosion conditions. For both, AFC joints and full scale AFCs, the corrosion rate achieved during the corrosion testing was assessed.

Both AFC specimens were assembled using Bisalloy 500 shims of $6 \mathrm{~mm}$ thickness, and Grade 300 steel plates of $20 \mathrm{~mm}$ thickness for the fixed, slotted, and cap plates. They were clamped using 2 M16 Grade 8.8 structural galvanized bolts of $110 \mathrm{~mm}$ length with unthreaded length of $72 \mathrm{~mm}$ and threaded length of $38 \mathrm{~mm}$. Bolts were assembled using a structural washer of $4 \mathrm{~mm}$ thickness, a flat washer of $4 \mathrm{~mm}$ thickness, and a single Belleville washer of $2.5 \mathrm{~mm}$ at the fully squashed condition, as shown in Figures 1a-e. Belleville washers were used to reduce the variation of the clamping force on the bolts due to degradation of the sliding surfaces [1]. In both configurations, the slotted plate has a slot length of $220 \mathrm{~mm}$ and a bolt grip length of $82.5 \mathrm{~mm}$. The bolt grip length was calculated as $3 \times 20 \mathrm{~mm}$ for the plates, plus $2 \times 6 \mathrm{~mm}$ for the shims, plus $4.0 \mathrm{~mm}$ for the structural washer, $4.0 \mathrm{~mm}$ for the flat washer, and $2.5 \mathrm{~mm}$ for the flattened Belleville washer. 


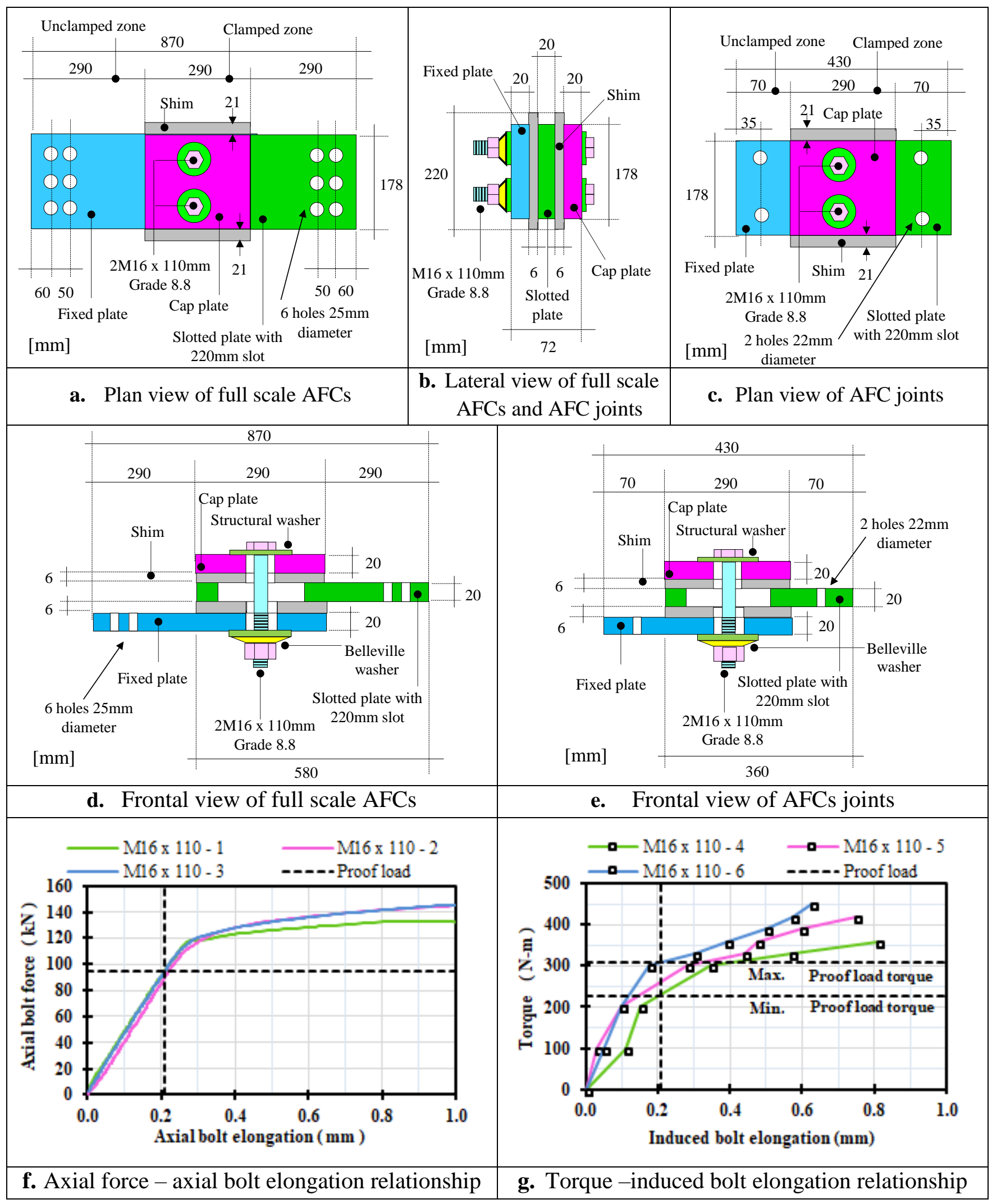

Figure 1. Dimensions of full scale AFCs and AFCs joints, and assembly relationships 
Both AFC specimens comprised one clamped zone and two unclamped zones. The clamped zone is defined as the zone carrying the compression induced by the 2 M16 Grade 8.8 galvanized bolts. This clamped zone has same dimensions for both configurations, as shown in Figures 1a-e, since the interest of this research is describing the behaviour of this zone during the corrosion testing, and the effects of corrosion in the hysteretic behaviour of this zone. The unclamped zones are defined as the zones of the fixed and slotted plate free of the compression induced by the 2 M16 Grade 8.8 galvanized bolts, and that are located beside the cap plate. The unclamped zones for full scale AFCs are used to allow the slotted plate to slide across one half of the slot length during the quasi-static testing, and for AFC joints, these zones are only used for manipulating the samples during the corrosion testing. For that reason, the unclamped zones of the AFC joints and full scale AFCs have the same width, but the length of the unclamped zone of the AFC joints is $24.1 \%$ of the length of the unclamped zone of the full scale AFCs, as shown in Figures 1a-e.

\subsection{Surface treatments}

Prior to assembly the AFC joints and the full scale AFCs, the entire surfaces of the fixed plate, of the slotted plate, the cap plate, and the shims were treated. Treatment was not applied to bolt holes. Surface treatments include: cleaned surfaces, sweep blasted surfaces, alkyd coated surfaces, and zinc coated surfaces. These surface treatments are described in Table 1. Table 1 also presents for each surface treatment, the AFC specimen initial mass, $W$, and the AFC specimen external area, $A$. The AFC specimen initial mass, $W$, is defined as the mass of an AFC specimen before corrosion. It was calculated as the average of the mass obtained experimentally for 3 AFC specimens after surface treatment was applied and assembly was undertaken. The AFC specimen external area, $A$, is defined as the area of an AFC specimen 
that can be exposed to the corrosive agent during the corrosion testing, and it considers the plan, lateral, and frontal areas of the AFC specimen plates presented in Figures 1a - e ignoring the bolts and washers at the clamped zone. The AFC specimen external area, $A$, was calculated as twice the lateral area plus twice the frontal area ignoring the bolt holes and the slot, and plus twice the plan area considering the bolt holes at the unclamped zones, ignoring the bolt holes at the clamped zone, and considering four times the plan area of the shims at both sides of the clamped zone.

Table 1 Description of surface treatments applied on full scale AFCs and AFCs joints, and AFC joints initial mass and external area

\begin{tabular}{|c|c|c|c|c|c|c|}
\hline $\begin{array}{l}\text { Surface } \\
\text { treatment }\end{array}$ & $\begin{array}{l}\text { Dry Film } \\
\text { Thickness } \\
\text { DFT } \\
\text { microns }\end{array}$ & Surface treatment description & $\begin{array}{l}\text { AFC joint } \\
\text { initial mass } \\
\quad \text { W } \\
\text { grams }\end{array}$ & $\begin{array}{c}\text { AFC joint } \\
\text { external } \\
\text { area } \\
\text { A } \\
\text { cm }^{2}\end{array}$ & $\begin{array}{l}\text { Full scale } \\
\text { AFC } \\
\text { initial } \\
\text { mass } \\
\text { W } \\
\text { grams }\end{array}$ & $\begin{array}{c}\text { Full scale } \\
\text { AFC } \\
\text { external } \\
\text { area } \\
\text { A } \\
\text { cm }^{2}\end{array}$ \\
\hline Cleaned & $\begin{array}{c}\text { Not } \\
\text { applicable }\end{array}$ & $\begin{array}{l}\text { Removing impurities over all } \\
\text { surfaces of plates and shims by } \\
\text { means of a rubbing the surfaces with } \\
\text { rag impregnated of thin layer of } \\
\text { acetone }\end{array}$ & 31854.0 & 2727.6 & 43352.0 & 4441.5 \\
\hline $\begin{array}{l}\text { Sweep } \\
\text { blasted }\end{array}$ & 40 & $\begin{array}{l}\text { Blasting all surfaces of plates and } \\
\text { shims with Ilmenite sand with a size } \\
\text { of } 150 \text { microns - 180microns as } \\
\text { defined by [8]. }\end{array}$ & 31849.0 & 2727.6 & 43420.0 & 4441.5 \\
\hline $\begin{array}{c}\text { Coated } \\
\text { with alkyd }\end{array}$ & 40 & $\begin{array}{c}\text { Application of Alkyd Primer over } \\
\text { all surfaces of plates and shims as } \\
\text { defined by [9]. }\end{array}$ & 31967.0 & 2727.6 & 43552.0 & 4441.5 \\
\hline $\begin{array}{c}\text { Coated } \\
\text { with zinc }\end{array}$ & 75 & $\begin{array}{l}\text { Application of inorganic Zinc } \\
\text { Silicate over all surfaces of plates } \\
\text { and shims as defined by [9]. }\end{array}$ & 31911.0 & 2727.6 & 43408.0 & 4441.5 \\
\hline
\end{tabular}

\subsection{AFC assembly}

A total of 12 full scale AFCs and 12 AFC joints were assembled and divided into 4 groups of 3 specimens each. The 4 groups of full scale AFCs and 4 groups of AFC joints matched 
with the 4 types of the surface treatment defined in Table 1. Full scale AFCs and AFCs joints were assembled by tensioning bolts in the clamped zone of the specimen up to the proof load of $95 \mathrm{kN}$ for a Grade $8.8 \mathrm{M} 16$ bolt using the torque control method. In this method, a bolt is gradually tensioned to a torque that develops an axial elongation equivalent to the elongation that the bolt develops when it reaches the proof load in axial tensile testing. This torque is termed proof load torque, and the elongation of the bolt, when it reaches the proof load in axial tensile testing, is termed proof load elongation.

The proof load elongation of $0.21 \mathrm{~mm}$, which occurred over the grip length of $82.5 \mathrm{~mm}$, was read from an axial tensile testing relationship from 3 bolts using the proof load value, as shown in Figure 1e. The proof load torque of $270 \mathrm{~N}-\mathrm{m}$ was assessed as the average of the maximum and minimum torques read from a torque - induced bolt elongation relationship for 3 bolts using the proof load elongation value, as shown in Figure 1f.

\subsection{Corrosion testing}

Full scale AFCs and AFC joints were subjected to an accelerated cyclic corrosion regime capable of producing an equivalent uniform corrosion rate greater than $80 \mu \mathrm{m} / \mathrm{year}$, which represents the minimum corrosion rate exhibited by mild steel in a very high corrosive environment based on site corrosion studies [9]. The accelerated corrosive regime comprised 120 cycles with a duration per cycle of 1 day. Each cycle comprises two stages: i) an immersion stage with a duration of 12 hours, where AFC specimens were immersed in a salt water solution at $40^{\circ} \mathrm{C}$ with a salt concentration of $3.5 \%$ and an oxygen concentration of approximately $5.7 \mathrm{mg} / \mathrm{lt}$, as shown in Figure $2 \mathrm{a}$; and ii) a steaming stage with a duration of 12 hours, where the AFC specimens were exposed to steam at $40^{\circ} \mathrm{C}$ produced from heating 
the salt water solution used in the immersion stage, as shown in Figure 2a. Every 10 cycles, the salt water solution was changed, the AFC specimens were cleaned with a clean water blaster to remove any of the corrosive product, and the mass of the AFC specimens was determined after water cleaning.

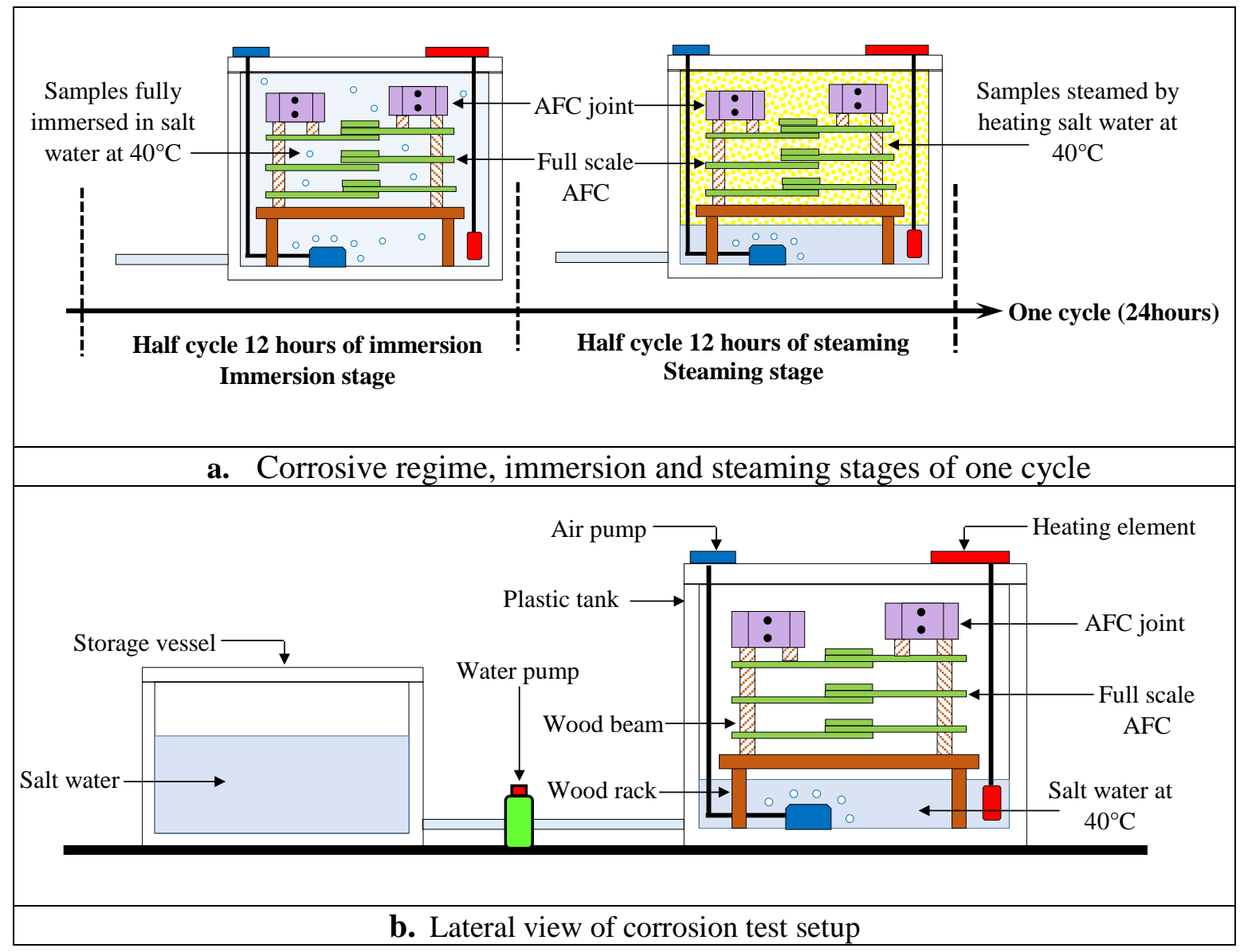

Figure 2. Corrosion test setup and corrosive regime for full scale AFCs and AFCs joints

The corrosion test setup comprised a plastic tank equipped with a heating element with a digital temperature controller for heating the salt water solution, an air pump for injecting air to the salt water solution, and a storage vessel equipped with a water pump for filling or draining the salt water solution of the plastic tank. This system is shown in Figure $2 \mathrm{~b}$. AFC specimens were placed in the two top vertical thirds of the plastic tank depth supported on a 
wood rack, and separated vertically and horizontally to allow each AFC specimen to develop its own corrosion mechanism, as also shown in Figure 2b.

\subsection{Assessment of corrosion rate in AFCs}

The corrosion rate, $C R$, was calculated from the mass loss of the AFC specimens subject to accelerated corrosion conditions. The corrosion rate is expressed in micrometres per year ( $\mu \mathrm{m} /$ year) and it can be determined [10]:

$$
C R=36500 \times \frac{W \times P}{A \times T \times D}
$$

Where $W$ is the initial mass of the AFC specimen in grams, $P$ is the mass loss expressed as percentage of the initial mass of the AFC specimen, $A$ is the external area of the AFC specimen in $\mathrm{cm}^{2}, T$ is the time of duration of the corrosive regime in days or cycles (note that 1 cycle $=1$ day), and $D$ is the density of the material of the AFC specimen in $\mathrm{gr} / \mathrm{cm}^{3}$.

\subsection{Assessment of equivalent real corrosion exposure time}

The equivalent real corrosion time, $\operatorname{Tr}$, is defined as the time in years that would be required for the AFC specimens to develop the minimum design corrosion penetration in a very high corrosive environment ( $45 \mu \mathrm{m} /$ year) [11]. The equivalent corrosion time, $\mathrm{Tr}$, in years can thus be determined:

$$
\operatorname{Tr}=100 \times\left[\frac{W \times P}{A \times D \times 45}\right]
$$


Where $W$ is the initial mass of the AFC specimen in grams, $P$ is the mass loss expressed as percentage of the initial mass of the AFC specimen, $A$ is the external area of the AFC specimen in $\mathrm{cm}^{2}, D$ is the density of the material of the AFC specimen in $\mathrm{gr} / \mathrm{cm}^{3}$, and 45 is the minimum design corrosion rate defined for mild steel in a very high corrosive environment in $\mu \mathrm{m} /$ year [11].

\subsection{Quasi-static testing}

Quasi-static testing was undertaken in full scale AFCs with surface treatment after assembly, and in full scale AFCs with surface treatment and corrosion after drying at room temperature over 30 days until reaching constant mass. This approach ensures the sliding surfaces of the full scale AFCs were dried. Full scale AFCs were quasi-statically tested using a shake table to provide a strictly horizontal input at the required force level, thus minimizing prying

effects that reduce AFC strength $[5,6]$. The test setup comprised a fixed bracket attached to a reaction frame bolted to a reaction floor, and a moving bracket attached to a reaction frame bolted to a shaking table. Full scale AFCs were connected using 6 M24 Grade 8.8 bolts at each end. A load cell was placed between the fixed bracket and the reaction frame, and a potentiometer was placed across the connection stroke. Details are shown in Figure 3a.

The displacement inputs are defined in Figure $3 \mathrm{~b}$ and comprise 21 sinusoidal cycles with a maximum velocity of $10 \mathrm{~mm} / \mathrm{s}$ and amplitudes varying from 0 to $\pm 95 \mathrm{~mm}$. This amplitude is $95 \%$ of the full $220 \mathrm{~mm}$ slot length. The peak velocity of $10 \mathrm{~mm} / \mathrm{s}$ is slow enough to minimise velocity dependent effects [3] and it was chosen since the aim of this research is describing the effect of surface treatments and corrosion on the hysteretic behaviour of AFCs under 
quasi-static conditions. Each AFC was run twice with no bolt re-tensioning and with a 30minute break for cooling the AFC; thus, removing the friction heat from the first run.

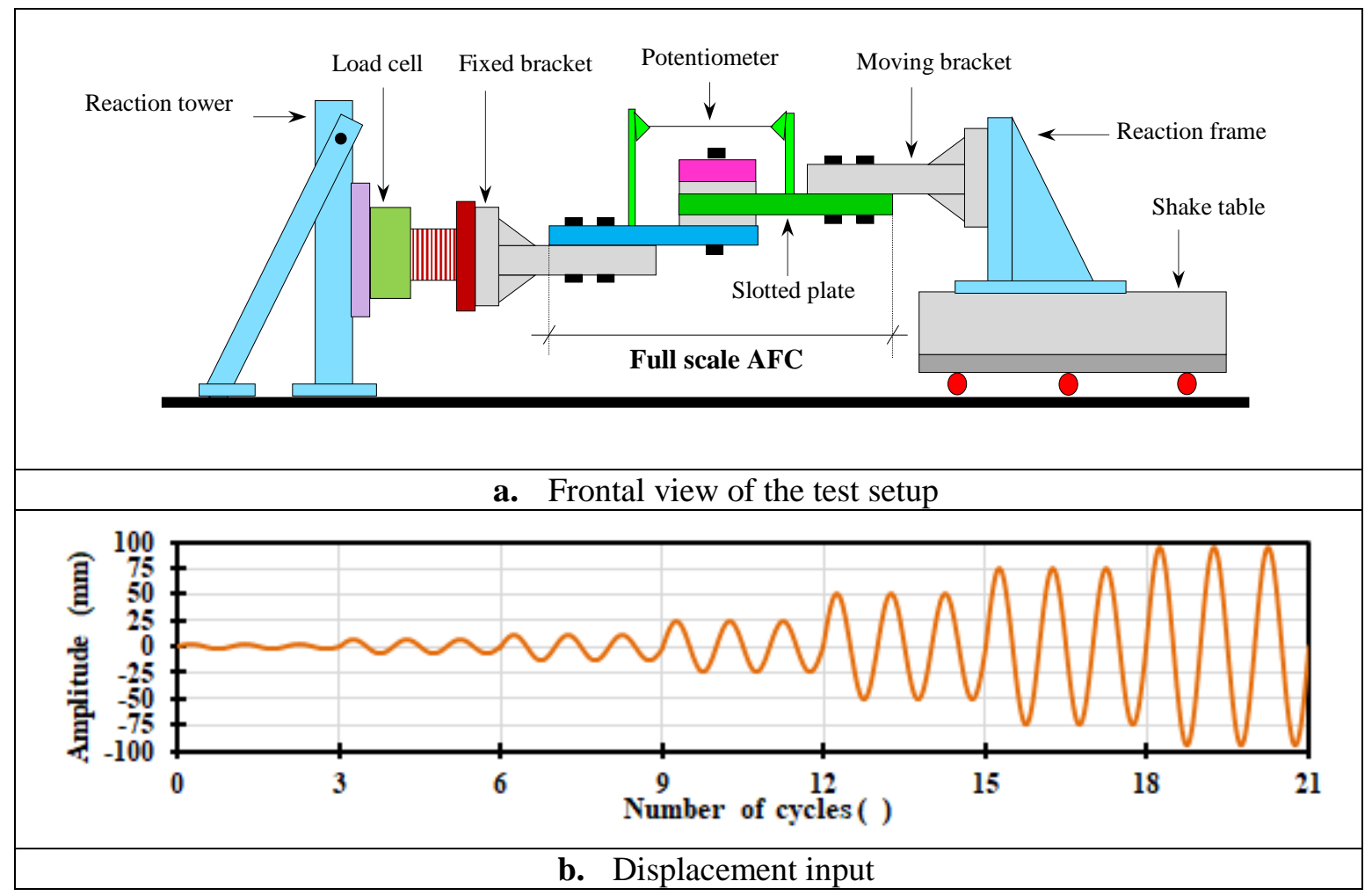

Figure 3. Setup of AFCs and displacement input.

\subsection{Assessment of experimental AFC strength}

The experimental AFC strength, $S$, of a full scale AFC at a given hysteresis loop amplitude was assessed by reading the force values at the four corners and at the two zero displacement points of the hysteresis loop, as shown in Figure 4. 


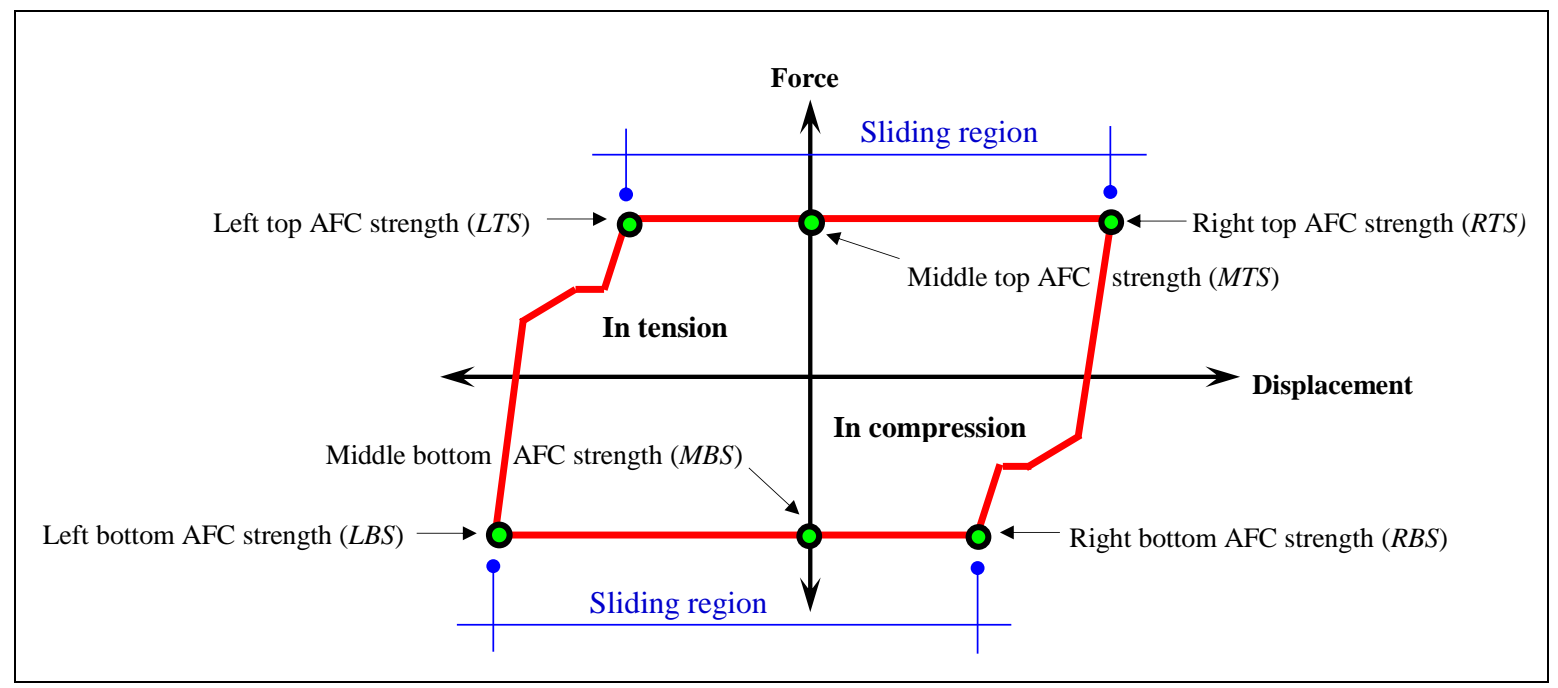

Figure 4. Assessment points of experimental AFC strength at a given hysteresis loop amplitude

The average experimental AFC strength, $S a$, was assessed as the average absolute value of the tension and compression sliding regions of the hysteresis loop, and it is defined:

$$
S a=\left[\frac{(L T S+M T S+R T S)+|L B S+M B S+R B S|}{6}\right]
$$

Where, LTS, MTS, and RTS are the experimental AFC strengths at the tension sliding region of the hysteresis loop, and $L B S, M B S$, and $R B S$ are the experimental AFC strengths at the compression sliding region of the hysteresis loop, as shown in Figure 4.

\subsection{Assessment of the effective friction coefficient}

The effective friction coefficient is a non-dimensional factor defined as the ratio between the AFC strength and the total clamping force induced by the bolts on the AFC [12]. This friction coefficient is termed effective because it is not constant due to any degradation of the AFC sliding surfaces, any surface coating [3], and the materials used [13]. For ease, it is evaluated 
by considering that the clamping force remains constant regardless of any degradation of the sliding surfaces. The effective friction coefficient, $\mu_{e}$, can thus be determined:

$$
\mu_{e}=\frac{S}{m \times n \times F_{\text {proof }}}
$$

Where, $S$ is the experimental AFC strength, $m$ is the number of bolts, $n$ is the number of shear planes, and $F_{\text {proof }}$ is the proof load per bolt.

\subsection{Assessment of the hysteresis loop stability}

The hysteresis loop stability is defined as how repetitive is the shape of the hysteresis loop as the displacement amplitude increases. It is assessed qualitatively. The hysteresis loop is termed stable when the loop shape is repeated with the hysteresis loop amplitude, and unstable when the loop shape is not repeated with the hysteresis loop amplitude.

\section{RESULTS AND ANALYSIS}

\subsection{Types of corrosion developed in AFCs specimens}

General corrosion, defined as the uniform loss of mass accompanied by the uniform presence of corrosion product and surface deterioration from smooth to very rough, was developed in AFC specimens with the four surface treatments, as shown in Figure 5. In the present investigation, the general corrosion also includes shallow pits, which were observed over the surface of the AFC specimens. At the external surface of AFC specimens, general corrosion was significantly developed across the full surfaces of the four surface treatments, and the greatest general corrosion was developed by AFCs with cleaned, and sweep blasted surfaces, 
and the lowest by AFCs with zinc coated surfaces, as shown in Figure 5. At the internal surfaces of AFC specimens, the corrosion process was likely that of crevice corrosion but had the same general appearance as the external corroded surfaces. Some corrosion was observed across the full internal surfaces of AFC specimens with cleaned and sweep blasted surfaces, and only limited corrosion initiating from the edges to internal regions of the internal surfaces in AFC specimens with alkyd and zinc coatings, as shown in Figure 5.

Filiform corrosion, defined as the coating deterioration due to grow of white fine filaments in a random pattern that turned the coating in a light rusty veined surface with no major changes in smoothness or mass [14], was developed in AFC specimens with sweep blasted, alkyd coating, and zinc coating treatments, as shown in Figure 5. Filiform corrosion was developed prior to general corrosion, and it first developed on the external surfaces and then on the internal surfaces of AFC specimens, as shown in Figures $5 \mathrm{c}-\mathrm{d}$.

Galvanized bolts developed first filiform corrosion and then general corrosion from the external to the internal surfaces of the AFC specimens, as shown in Figure 5. Greatest general corrosion was developed in bolts of AFCs with alkyd and zinc coated surfaces, as shown in Figures 5c - d. 


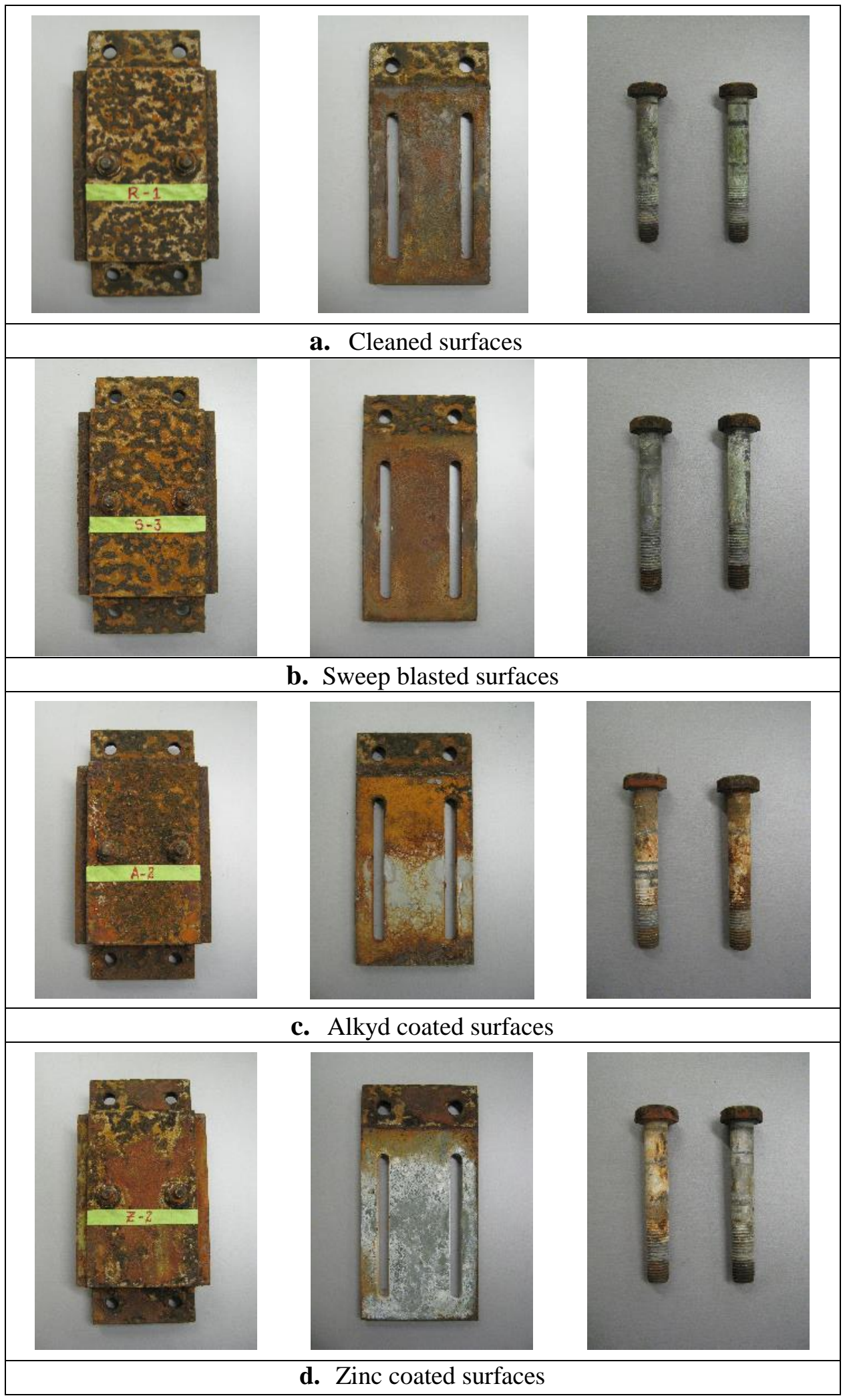

Figure 5. AFC joint and slotted plate with the four surface treatments and Grade 8.8 galvanized bolts after corrosion testing 


\subsection{Corrosive mechanism of AFCs}

Figure 6 shows the average corrosion rate and the average mass loss for 3 AFC joints, and for 3 full scale AFCs exhibited by each of the four surface treatments during the corrosion testing. Corrosion rates were assessed with Equation 1 using a material density, $D$, of $7.85 \mathrm{gr} / \mathrm{cm}^{3}$, the percentages of mass loss, $P$, and the exposure times, $T$, indicated in Figure $6 \mathrm{~b}$, and the external areas, $A$, and the initial masses, $W$, indicated in Table 1. In Figure 6 the mass loss percentage and the corrosion rate for full scale AFCs are only presented for the second half of the corrosion testing, since the cleaning and mass control process defined in Section 2.4 were undertaken for these specimens only on this period in order to check if by the end of the corrosion testing, full scale AFCs and AFC joints would develop the same corrosion mechanisms.

Two types of corrosive mechanisms can be observed in Figure 6 according to the surface treatment:

i. For AFC joints with cleaned surface treatment, the corrosion rate increased almost linearly as the corrosive cycles increase, as shown in Figure 6a. This linearly increasing corrosion rate implies a parabolic decreasing mass with time as shown in Figure 6b. This corrosive mechanism is based on mass loss produced by general corrosion, which is activated at the initial corrosive cycles due to absence of a coating barrier that protects AFC joint surfaces from corrosive deterioration. This mechanism is similar to that developed for full scale AFCs, since the mass loss percentage and the corrosion rate trends exhibited for full scale AFCs had the same trend as those exhibited by AFC joints, as shown in Figures $6 a-b$. Figures 6 and Table 2 show AFC joints and full scale AFCs with cleaned surface treatment 
underwent after 120 corrosive cycles a resulting total corrosion rate of $974.51 \mu \mathrm{m} /$ year and $848.26 \mu \mathrm{m} / \mathrm{year}$, for a total mass loss respect to the initial mass of $2.15 \%$ and $2.24 \%$, respectively. The corrosion rates for AFC joints and full-scale AFCs with cleaned treatment correspond to an equivalent real corrosion exposure time, $\operatorname{Tr}$, of $6.2-7.1$ years, as shown in Table 2. Here, the equivalent real corrosion exposure time, $\operatorname{Tr}$, was assessed according to Equation 2 using the mass losses described above, a material density, $D$, of $7.85 \mathrm{gr} / \mathrm{cm}^{3}$, the external areas, $A$, and the initial masses, $W$, indicated in Table 1.

Table 2. Mass loss, corrosion rate, and equivalent real corrosion exposure time for four different surface treatments after 120 corrosive cycles

\begin{tabular}{|c|cc|cc|cc|}
\cline { 2 - 7 } \multicolumn{1}{c|}{} & \multicolumn{2}{c|}{ Percentage of mass loss } & \multicolumn{2}{c|}{ Corrosion rate } & \multicolumn{2}{c|}{ Equivalent real exposure time } \\
& AFC joints & Full scale AFCs & AFC joints & Full scale AFCs & AFC joints & Full scale AFCs \\
Surface treatment & $\mathbf{P}$ & $\mathbf{P}$ & $\mathbf{T r}$ & $\mathbf{C R}$ & $\mathbf{T r}$ & $\mathbf{T r}$ \\
Cleaned surfaces & 2.15 & 2.24 & 974.51 & 848.26 & 7.1 & 6.2 \\
Sweep Blasted surfaces & 2.05 & 1.86 & 933.79 & 705.19 & 6.8 & 5.1 \\
Alkyd coated surfaces & 1.06 & 0.94 & 482.26 & 357.68 & 3.5 & 2.6 \\
Zinc coated surfaces & 0.25 & 0.16 & 111.75 & 61.36 & 0.8 & 0.4 \\
\hline
\end{tabular}

ii. For AFC joints with sweep blasted, alkyd coated, and zinc coated treatments, the corrosion rate is null for certain amount of corrosion cycles, and then it increased almost linearly as the corrosive cycles increase, as shown in Figure 6a. This corrosive mechanism keeps AFC joint mass almost constant for a certain number of cycles due to the development of filiform corrosion. However, subsequently, mass loss is activated due to general corrosion and it increased almost parabolic. This mechanism is similar to that developed for full scale AFCs, since the mass loss percentage and the corrosion rate trends exhibited for full scale AFCs had the same trend as those exhibited by AFC joints, as shown in Figures 6a. Figure 6b 
shows activation of mass loss occurred after 20,40, and 110 corrosive cycles, for AFC joints with sweep blasted, alkyd coated, and zinc coated treatments, respectively. Figure $6 \mathrm{~b}$ and Table 2 show after 120 corrosive cycles for AFC joints mass losses respect to the initial masses were $2.05,1.06,0.25 \%$, and for full scale AFCs were $1.86,0.94,0.16 \%$, for sweep blasted, alkyd coated, and zinc coated treatments, respectively. Figure 6a and Table 2 show after 120 corrosive cycles, AFC joints underwent resulting total corrosion rates of 933.79, 482.26, $111.75 \mu \mathrm{m} / \mathrm{year}$, and full scale AFCs underwent resulting corrosion rates of 705.19, 357.68, 61.36 $\mu \mathrm{m} / \mathrm{year}$, for sweep blasted, alkyd coated, and zinc coated treatments, respectively. These corrosion rates for AFC joints and full scale AFCs with sweep blasted, alkyd coated and zinc coated surfaces correspond to an equivalent real exposure corrosion times, $\operatorname{Tr}$, of $5.1-6.8,2.6-3.5$, and $0.4-0.8$ years, respectively, as shown in Table 2 . Here, the equivalent real exposure corrosion time, $T r$, was assessed according to Equation 2 using the mass losses described above, a material density, $D$, of $7.85 \mathrm{gr} / \mathrm{cm}^{3}$, the external areas, $A$, and the initial masses, $W$, indicated in Table 1 . 


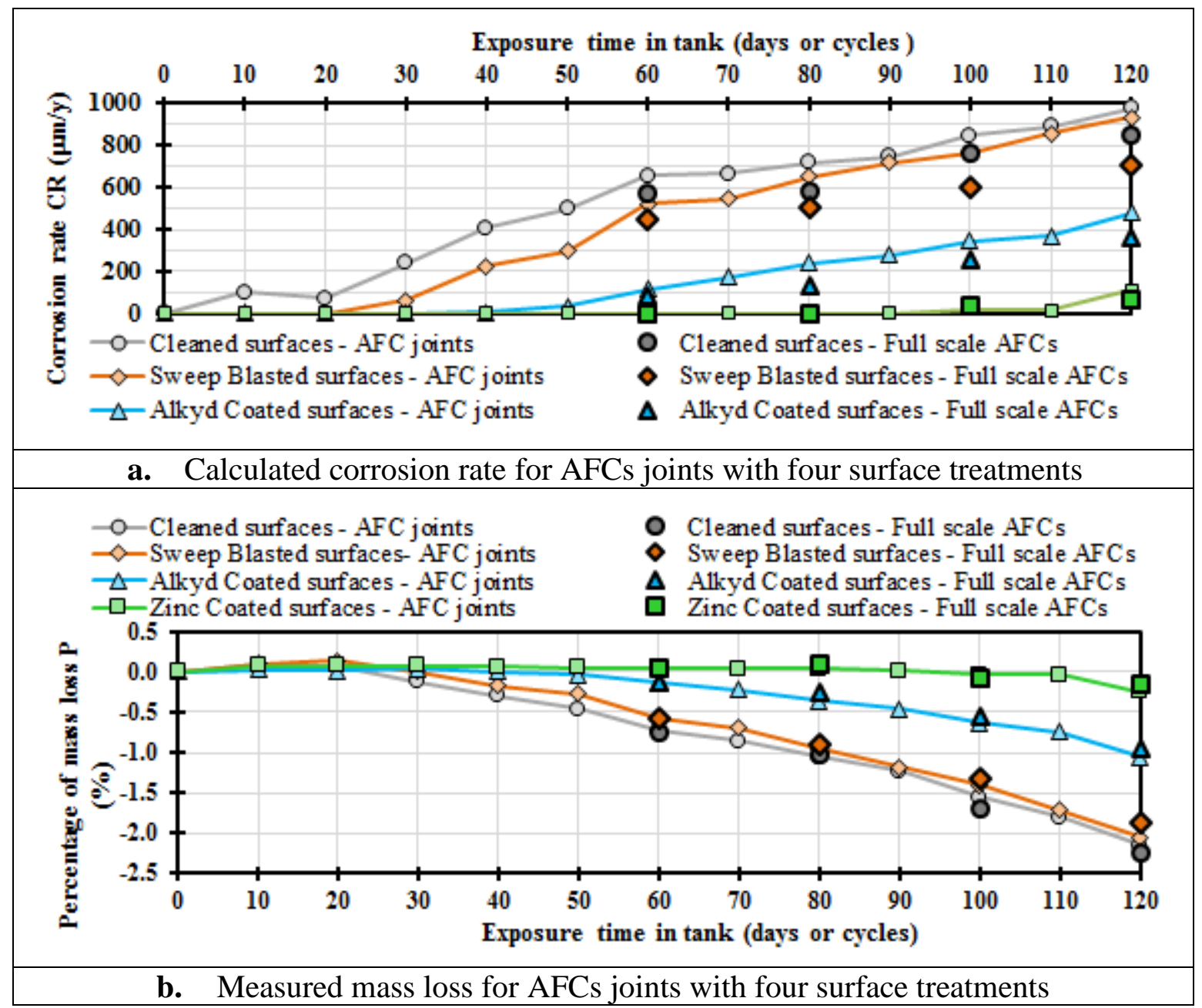

Figure 6. Measured mass loss and calculated corrosion rate for AFCs joints with four surface treatments

In the results described above, differences in percentage of mass loss and corrosion rate between the AFC joints and full scale AFCs are attributed to not undertaking the cleaning process defined in Section 2.4 in full scale AFCs during the first half of the corrosion testing, which slightly delayed the development of the corrosive mechanism in these specimens. It should be also noted that undertaking the cleaning process every 10 cycles resulted in a higher measured rate of corrosion that would occur if the corrosion product was not removed and the AFC specimens were allowed to reach steady state corrosion conditions. From the results 
described, it can be stated that AFCs with cleaning and sweep blasted surface treatments exposed to a high corrosive environment can undergo significant corrosion rates. Surface treatments such as alkyd coated and zinc coated surfaces can be used to delay corrosive effects. Finally, the most effective surface treatment is zinc coated surfaces.

\subsection{Effects of surface treatments on AFC hysteresis loop}

Figure 7 compares hysteresis loops of full scale AFCs before corrosion with cleaned surfaces with hysteresis loop of full scale AFCs before corrosion with sweep blasted, alkyd coated and zinc coated surfaces. Figure 7 shows the average AFC strength as defined in Section 2.8 may change, and hysteresis loop stability as defined in Section 2.10 may reduce depending on the type of surface treatment.

For sweep blasted surfaces, the hysteresis loop stability decreased in both runs, and the average AFC strength increased by $15 \%$ and $10 \%$ for the first and second run, respectively, when compared with the stability and the average AFC strength for cleaned surfaces, as shown in Figure 7a. These changes on the hysteresis loop stability and on the AFC strength for sweep blasted surfaces are attributed to the generation of a non-uniform surface roughness on the sliding surfaces during the sweep blasting procedure, which increases the friction coefficient and develops a non-uniform mechanism of sliding surfaces degradation. 

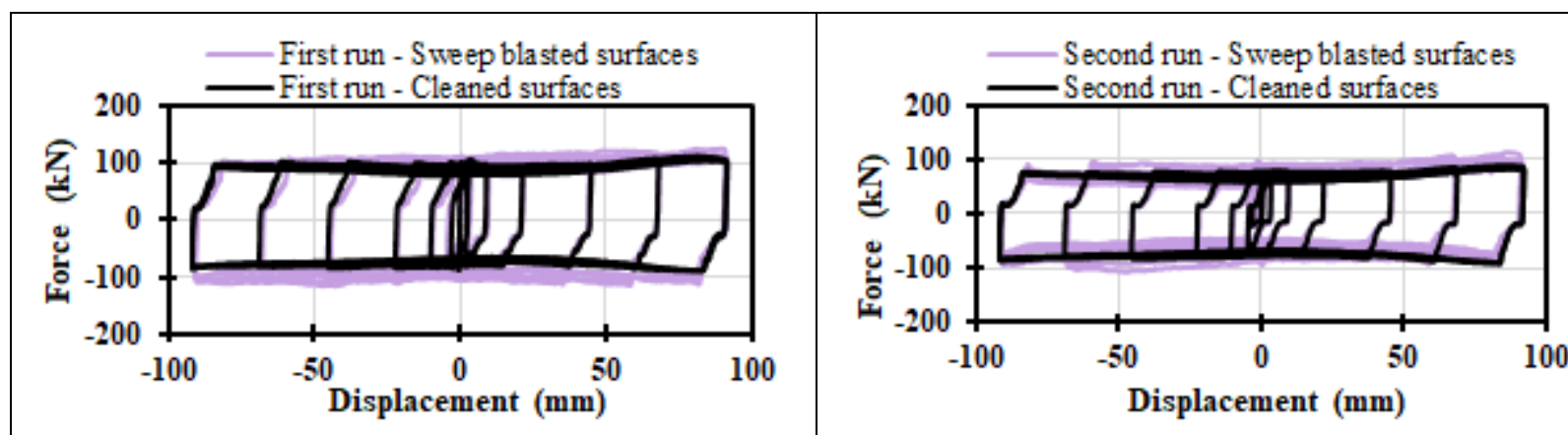

a. Sweep blasted surfaces and cleaned surfaces
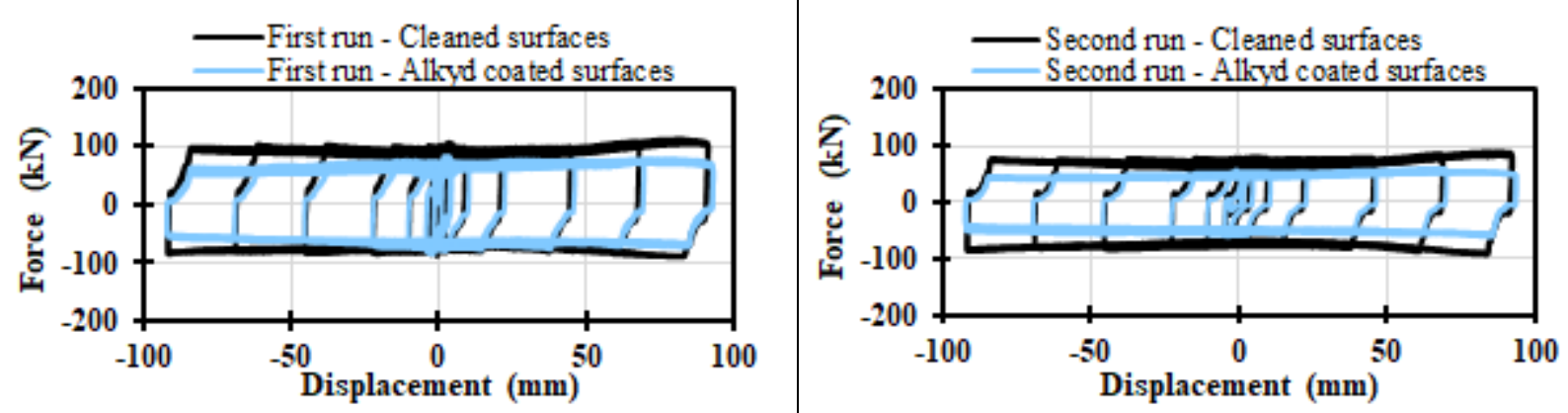

b. Alkyd coated surfaces and cleaned surfaces
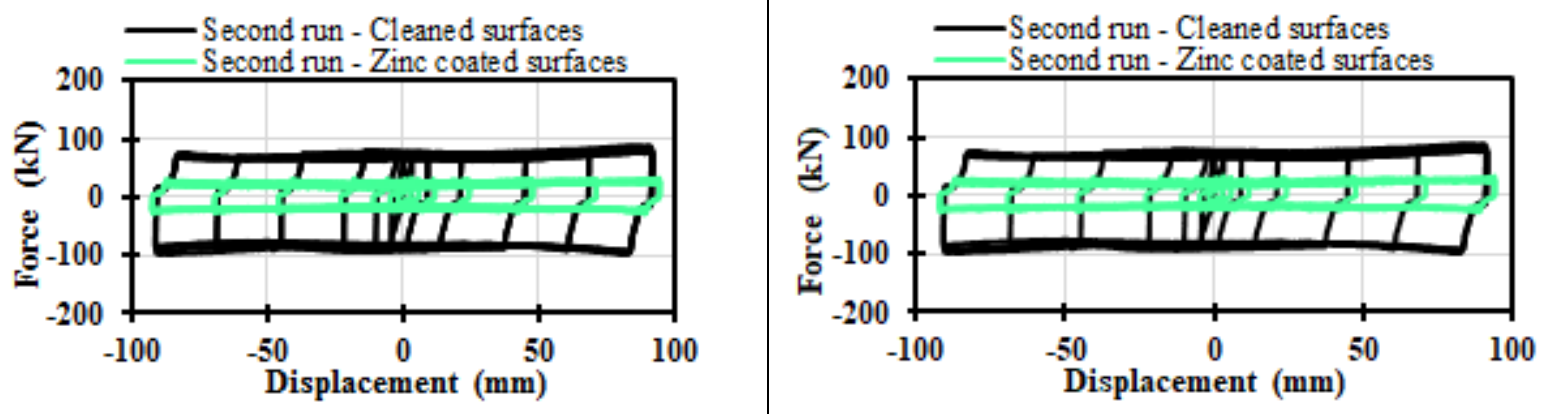

c. Zinc coated surfaces and cleaned surfaces

Figure 7. Hysteresis loop of full scale AFCs with four surface treatments before corrosion

For alkyd coated and zinc coated surfaces, the hysteresis loop stability did not change in both runs, although average AFC strength decreased after the initial sliding cycles when compared with the stability and the average AFC strength for cleaned surfaces, as shown in Figures $7 \mathrm{~b}$ - c. The average AFC strength reduced for alkyd coated and zinc coated surfaces in the first run by $29 \%$ and $62 \%$, respectively, and for the second run by $34 \%$ and $70 \%$, respectively, as shown in Figures $7 \mathrm{~b}-\mathrm{c}$. These reductions on the average AFC strength for alkyd coated and zinc coated surfaces are attributed to loss of bolt tension that occur when the coating at the 
sliding surfaces is either degraded or removed as the slotted plate slides. Once the degraded and removed coating particles are dragged and pushed out of the connection clamped zone, the connection plates move inwards reducing the bolt elongation and therefore reducing the bolt tension.

\subsection{Effects of corrosion on AFC hysteresis loop}

Figure 8 compares the hysteresis loop of the full scale AFCs after the corrosion testing to those before corrosion testing for the four surface treatments. For the four surface treatments, after corrosion, the overall hysteresis loop stability as defined in Section 2.10 decreased slightly, as shown in Figure 8. Also, for the four surface treatments, after corrosion, the AFC strength increased significantly in the initial sliding cycles. However, after the initial sliding cycles AFC strength decreased to an almost constant value approaching the AFC strength developed in the non-corroded condition, as shown in Figure 8. While for corroded cleaned and sweep blasted surfaces the almost stable AFC strength reduced with respect to the noncorroded case, for corroded alkyd coated and zinc coated surfaces it increased. Maximum increments in AFC strength in the initial sliding cycles with respect to average AFC strength in the non-corroded condition of $100 \%, 120 \%, 130 \%$, and $50 \%$ were developed for the corroded cleaned, sweep blasted, alkyd coated, and zinc coated surfaces, respectively, as shown in Figure 8. 

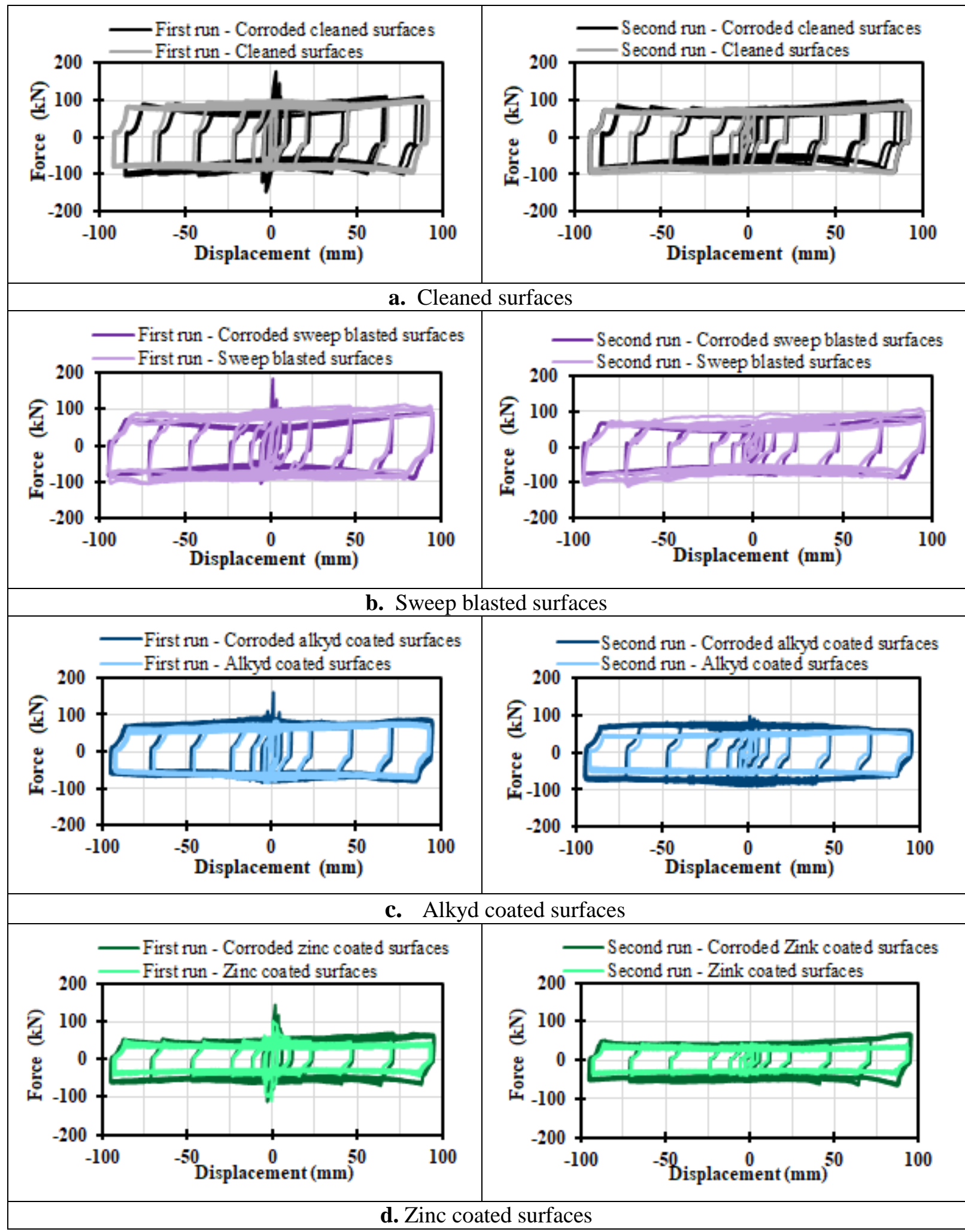

Figure 8. Hysteresis loops of full scale AFCs with four different surface treatments after and before corrosion testing 
The increased AFC strength in the initial sliding cycles can be interpreted as the force required to activate the sliding of the slotted plate to break free of corrosion product deposited at the external perimeter of the sliding interfaces. The reduction in hysteresis loop stability of the corroded AFCs is attributed to the gain in roughness of the sliding surfaces as result of the corrosion product developed at the internal clamped sliding surfaces. Reductions in the stable AFC strength by corroded AFCs with cleaned and sweep blasted surfaces are attributed to losses of bolt tension presented when the plates moved inwards after the internal clamped sliding surfaces lose mass as a result of uniform corrosion. Increments in the stable AFC strength by corroded AFCs with alkyd and zinc coated surfaces are attributed to increments in bolt tension presented when the plates moved outwards as the corroded product is built at the internal clamped surfaces as a result of filiform corrosion.

\subsection{Effects of surface treatments and corrosion on the effective friction coefficient of AFCs}

The effective friction coefficient, $\mu e$, for full scale AFCs with the four surface treatments before and after corrosion are shown in Figure 9. The effective friction coefficient before and after corrosion were assessed at hysteresis loop amplitudes of $3 \mathrm{~mm}, 6 \mathrm{~mm}, 12 \mathrm{~mm}, 25 \mathrm{~mm}$, $50 \mathrm{~mm}, 75 \mathrm{~mm}$, and $95 \mathrm{~mm}$ using Equation 4 considering $m=2, n=2, F_{\text {proof }}=95 \mathrm{kN}$, and $S$ as the average strength of 3 full scale AFCs using the methodology described in Section 2.8.

Figures $9 \mathrm{a}-\mathrm{d}$ shows $\mu e$ before corrosion is dependent on the surface treatment. For the four surface treatments, $\mu e$ varies with the hysteresis loop amplitude, for hysteresis loop amplitudes less than $20 \mathrm{~mm}$, but is almost constant for hysteresis loop amplitudes greater than 20mm. In the first run, cleaned, sweep blasted, alkyd coted, and zinc coated surfaces exhibited values of $\mu e$ of $0.20-0.22,0.20-0.25,0.18-0.20$, and $0.07-0.21$, respectively, 
and in the second run $\mu$ reduced to $0.19-0.21,0.17-0.21,0.14-0.15$, and $0.07-0.08$, respectively, as shown in Figures $9 \mathrm{a}-\mathrm{d}$ and Table 3. These values show that by sweep blasting AFC surfaces $\mu e$ increases slightly, and by coating with alkyd and zinc, $\mu e$ reduces. The greatest reductions in $\mu e$ correspond to zinc coated surfaces. These values also show $\mu e$ reduces from the first to the second run due to loss of bolt tension linked to degradation of sliding surfaces.

Table 3. Calculated effective friction coefficients for four different surface treatments in the corroded and non-corroded conditions

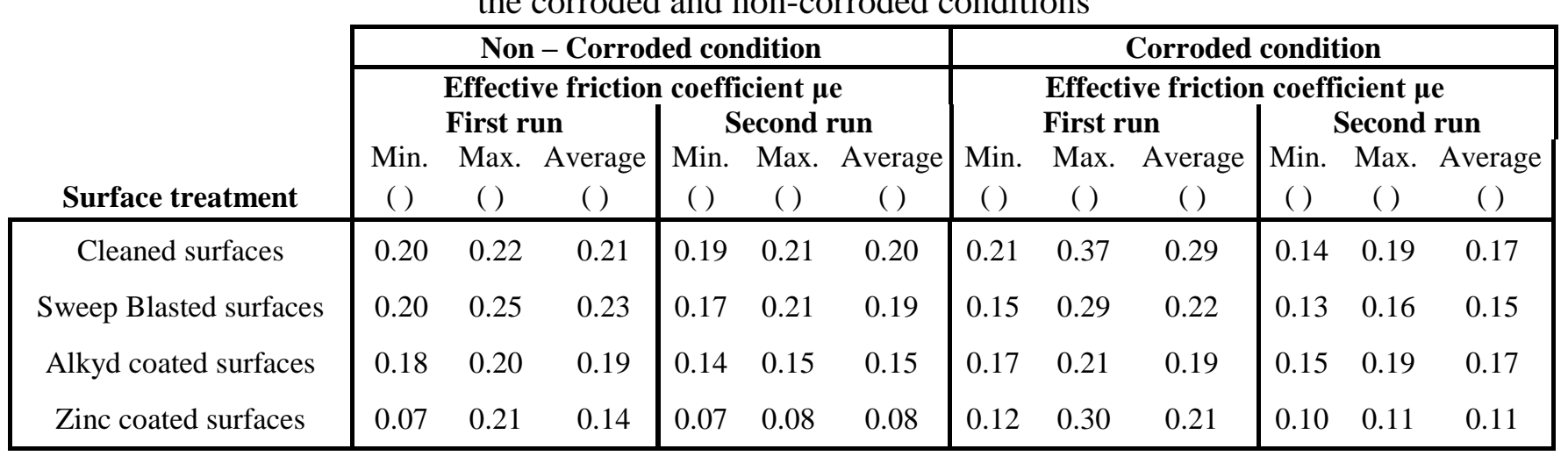

Figure $9 \mathrm{e}-\mathrm{h}$ shows how $\mu e$ depends on corrosion. For the four surface treatments, in the first run for hysteresis loop amplitudes smaller than $6 \mathrm{~mm}, \mu e$ exhibited by corroded AFCs was greater than $\mu e$ exhibited by AFCs with no corrosion. These increased values of $\mu e$ for corroded AFCs respect with $\mu e$ for non-corroded AFCs correspond to the increased AFC strength developed by the connection when removing the corrosion product to activate the sliding mechanism of the slotted plate as described in Section 3.4. For hysteresis loops amplitudes greater than $6 \mathrm{~mm}$ in the first run, and for whole hysteresis loop amplitudes in the second run, while corroded AFCs with cleaned, and alkyd coated surfaces exhibited $\mu e$ values near to $\mu e$ values exhibited by AFCs with no corrosion, corroded AFCs with sweep blasted surfaces and zinc coated surfaces exhibited $\mu e$ values lower and greater than $\mu e$ values exhibited by AFCs with no corrosion, respectively, as shown in Figures $9 \mathrm{e}-\mathrm{h}$. 


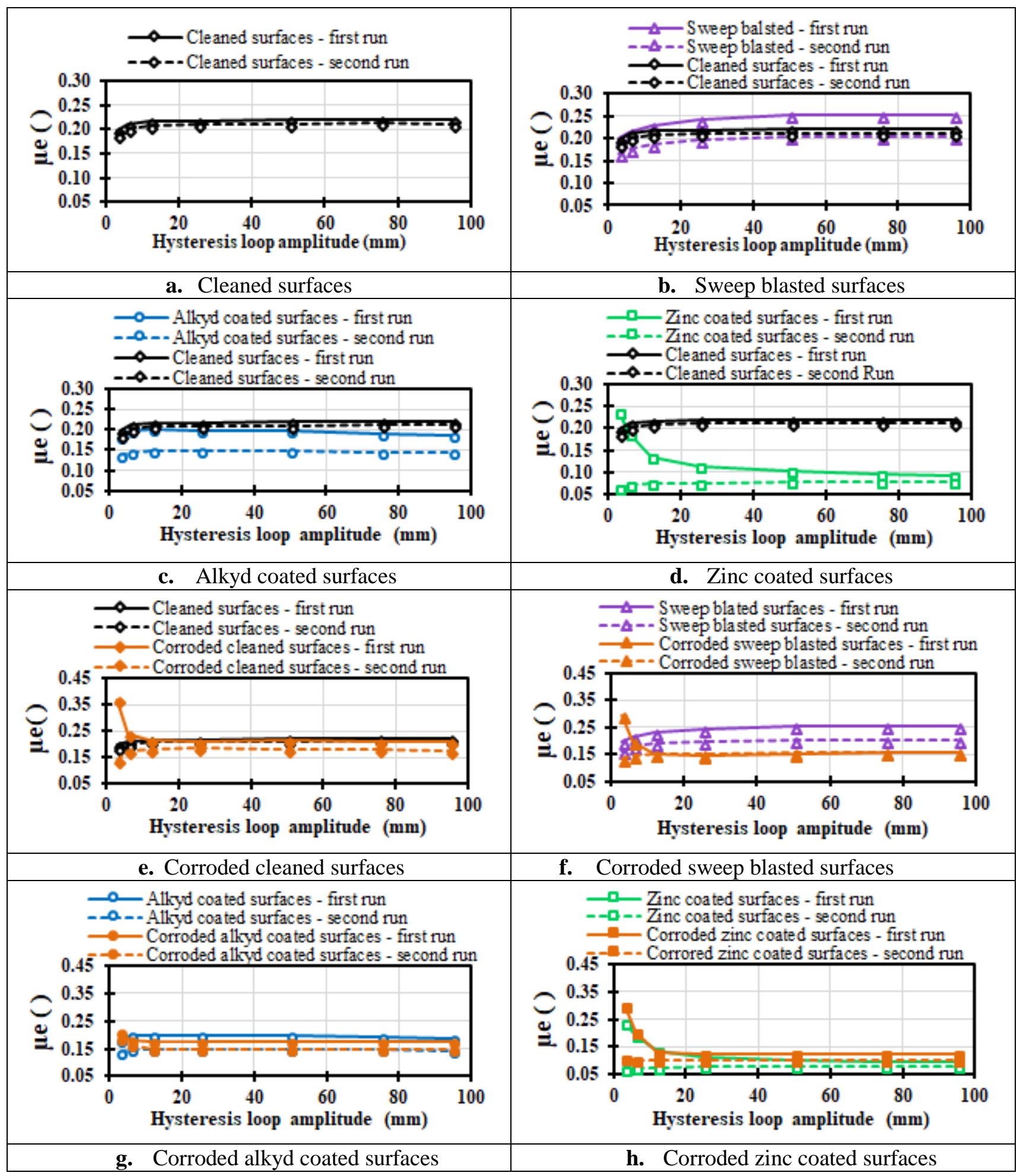

Figure 9. Effective friction coefficient, $\mu e$, of full scale AFCs with four different surface treatments before and after corrosion testing 
Figures $9 \mathrm{e}-\mathrm{h}$ also show that the greatest increase and the greatest reduction in $\mu e$ due to corrosion were exhibited by AFCs with cleaned and sweep blasted surfaces, respectively. The greatest increase in $\mu e$ was exhibited by AFCs with cleaned surfaces, since this surface treatment developed the greatest corrosion rate, thus requiring the greatest force to remove the corrosion product at the external surfaces for activating the sliding mechanism of the slotted plate, and therefore producing the greatest increase in $\mu e$. The greatest reduction in $\mu e$ was exhibited by AFCs with sweep blasted surfaces, since this surface treatment developed the greatest corrosion at the sliding surfaces, thus producing the greatest loss of bolt tension when the slotted plate removed simultaneously corrosion product at the sliding surfaces and surface treatment, and therefore producing the greatest reduction in $\mu e$.

In the first run, after corrosion, cleaned, sweep blasted, alkyd coted, and zinc coated surfaces exhibited values of $\mu e$ of $0.21-0.37,0.15-0.29,0.17-0.21$, and $0.12-0.30$, respectively, and in the second run $\mu e$ reduced to $0.14-0.19,0.13-0.16,0.15-0.19$, and $0.10-0.11$, respectively, as shown in Figures $9 \mathrm{e}-\mathrm{h}$ and Table 3. Reductions in $\mu e$ from the first to the second run are due to removal of corrosion product and degradation at the sliding surface during the sliding of the slotted plate and that produced loss of bolt tension.

\section{MODEL OF AFC STRENGTH CONSIDERING SURFACE TREATMENTS IN THE CORRODED AND NON-CORRODED CONDITION}

The average AFC strength for the first run considering surface treatments effects, $S a$, is modelled using the dry friction theory of Coulomb, and it is defined:

$$
S a=m \times n \times F_{\text {proof }} \times \mu e_{a}
$$


Where, $m$ is the number of sliding interfaces, $n$ is the number of bolts, $F_{\text {proof }}$ is the proof load per bolt, and $\mu e_{a}$ is the average effective friction coefficient. For the four surface treatments, $\mu e_{a}$ was assessed as the average of the effective friction coefficients in Figures $9 \mathrm{a}-\mathrm{d}$ for the first run at hysteresis loop amplitudes of $3 \mathrm{~mm}, 6 \mathrm{~mm}, 12 \mathrm{~mm}, 25 \mathrm{~mm}, 50 \mathrm{~mm}, 75 \mathrm{~mm}$, and $95 \mathrm{~mm}$. Values of $\mu e_{a}$ are presented in Table 4 , and these values can be used to assess $S a$ for the four surface treatments in the non-corroded and corroded condition using Equation 5.

Table 4. Average effective friction coefficients, overstrength and understrength factors for four different surface treatments in the corroded and non-corroded condition

\begin{tabular}{|c|c|c|c|c|c|c|}
\hline \multirow[b]{2}{*}{$\begin{array}{l}\text { Surface } \\
\text { treatment }\end{array}$} & \multicolumn{3}{|c|}{ Non - Corroded condition } & \multicolumn{3}{|c|}{ Corroded condition } \\
\hline & $\begin{array}{c}\boldsymbol{\mu e}_{\mathbf{a}} \\
(0-95) \mathrm{mm}^{*}\end{array}$ & $\begin{array}{c}\gamma \\
(0-95) \mathrm{mm} *\end{array}$ & $\begin{array}{c}\boldsymbol{\beta} \\
(0-95) \mathrm{mm}^{*}\end{array}$ & $\begin{array}{c}\gamma \\
(0-95) \mathrm{mm} *\end{array}$ & $(0-6) \mathrm{mr}$ & -95) $m m^{*}$ \\
\hline Cleaned surfaces & 0.21 & 0.66 & 1.28 & 0.61 & 2.21 & 1.28 \\
\hline $\begin{array}{l}\text { Sweep Blasted } \\
\text { surfaces }\end{array}$ & 0.23 & 0.65 & 1.32 & 0.37 & 1.35 & 1.07 \\
\hline $\begin{array}{l}\text { Alkyd coated } \\
\text { surfaces }\end{array}$ & 0.19 & 0.72 & 1.28 & 0.38 & 1.23 & 1.07 \\
\hline $\begin{array}{l}\text { Zinc coated } \\
\text { surfaces }\end{array}$ & 0.14 & 0.38 & 1.79 & 0.61 & 2.28 & 1.33 \\
\hline
\end{tabular}

To consider accuracy on tensioning bolts up to the proof load during assembly, cleanness of sliding surfaces during assembly, and variation of the effective friction with the hysteresis loop amplitude in the corroded and non - corroded condition, an understrength factor, $\gamma$, and an overstrength factor, $\beta$, were defined. These factors are used to account the maximum and minimum likely $S a$ termed understrength, $S a_{\min }$, and overstrength, $S a_{\max }$, respectively, and for the four surface treatments in the non-corroded and corroded condition they are defined:

$$
S a_{\text {min }}=\gamma \times m \times n \times F_{\text {proof }} \times \mu e_{a}
$$




$$
S a_{\text {max }}=\beta \times m \times n \times F_{\text {proof }} \times \mu e_{a}
$$

Values of $\gamma$ and $\beta$ for the four surface treatments are defined in Table 4. At the non-corroded condition, values of $\gamma$ and $\beta$ do not vary with the hysteresis loop amplitude. At the corroded condition, values of $\gamma$ and $\beta$ were defined for hysteresis loop amplitudes less than $6 \mathrm{~mm}$ and greater than $6 \mathrm{~mm}$, to model the increased AFC strength observed at the initial sliding cycles, and the almost constant AFC strength observed after the corrosion product is removed after the initial sliding cycles, respectively. Values of $\gamma$ and $\beta$ in the corroded condition, are applicable to the case when AFCs are exposed to a severe corrosive environment as that one described by AS/NZS 2312 [9]. Values of $\gamma$ and $\beta$ in Table 4 were obtained as the ratio between the lowest experimental AFC strength and the average experimental AFC strength in the case of $\gamma$, and as the ratio between the greatest experimental AFC strength and the average experimental AFC strengths in the case of $\beta$. The lowest, average, and greatest experimental AFC strengths, were determined from the AFC strengths assessed at hysteresis loop amplitudes of $3 \mathrm{~mm}, 6 \mathrm{~mm}, 12 \mathrm{~mm}, 25 \mathrm{~mm}, 50 \mathrm{~mm}, 75 \mathrm{~mm}$, and $95 \mathrm{~mm}$ using the methodology described in Section 2.8, for 3 full scale AFCs at each surface treatment, and in the corroded and non- corroded conditions.

Figure 10 shows for each surface treatment in the non-corroded and corroded condition a comparison between 126 experimental AFC strengths and the predicted average theoretical AFC strength, the understrength, and the overstrength. 


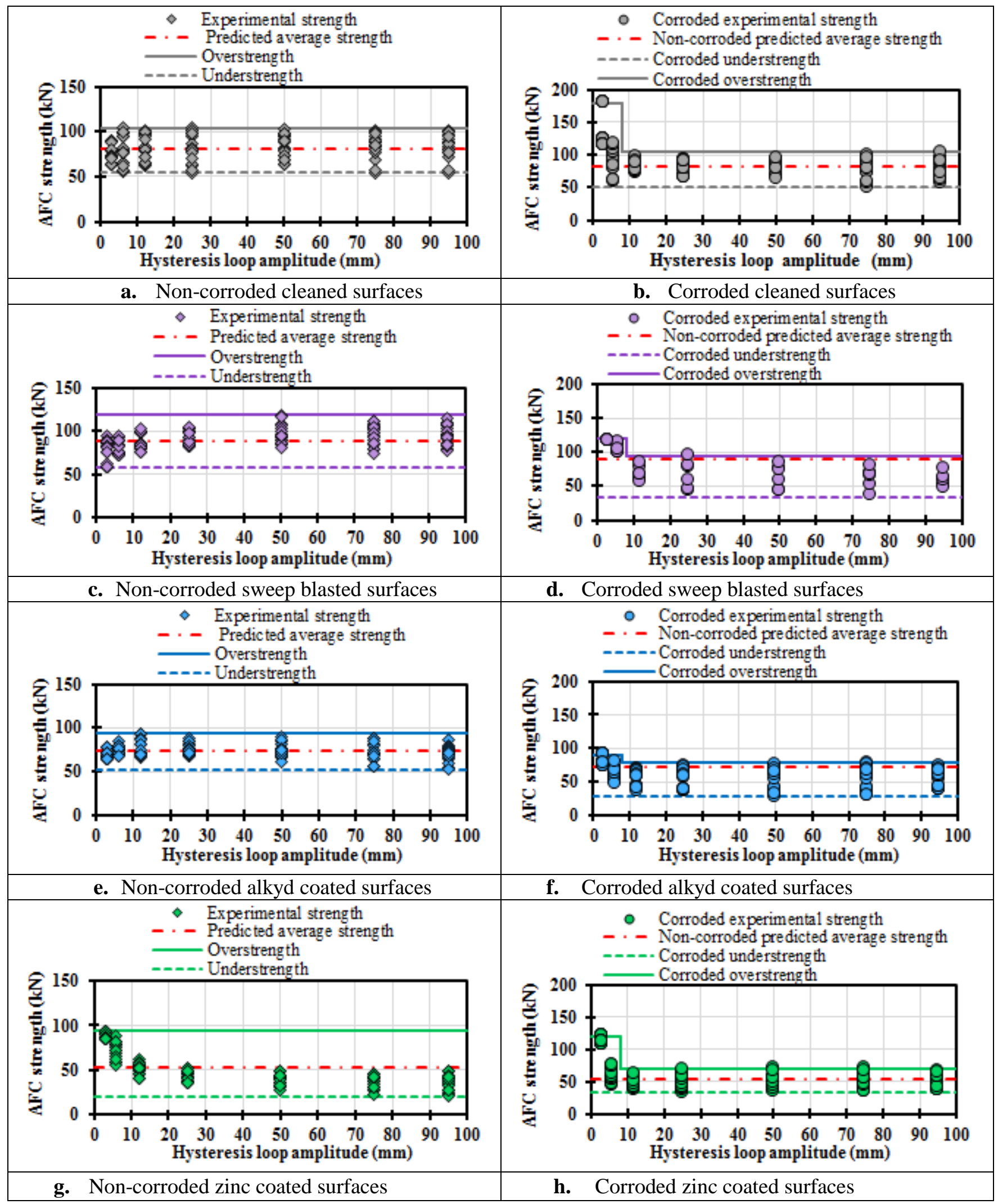

Figure 10. Comparison between AFC strength model and experimental AFC strength before and after corrosion for four surface treatments. 
In Figure 10 the 126 experimental AFC strengths at each surface treatment in the noncorroded and corroded conditions were assessed from 3 full scale AFCs; thus 42 experimental AFC strengths correspond to each full-scale AFC. For each full scale AFC, 6 experimental AFC strength were assessed at each of the hysteresis loop amplitudes of $3 \mathrm{~mm}, 6 \mathrm{~mm}, 12 \mathrm{~mm}$, $25 \mathrm{~mm}, 50 \mathrm{~mm}, 75 \mathrm{~mm}$ and $95 \mathrm{~mm}$ following the methodology described in Section 2.8. In Figure 10, in the corroded conditions, the greatest values at hysteresis loop amplitudes less than $6 \mathrm{~mm}$ correspond to the increased AFC strength required for removing the corroded product at the external surfaces to activate the sliding mechanism of the slotted plate. The average theoretical AFC strength, the understrength, and the overstrength were predicted using Equations $5-7$ using $m=2, n=2, F_{\text {proof }}=95 \mathrm{kN}$, and values of $\mu e_{a}, \gamma$, and $\beta$ defined in Table 4.

Figure 10 shows for each surface treatment in the non-corroded and corroded conditions, the overstrength and understrength envelope $100 \%$ of the experimental strengths. Table 5 shows the overstrength and understrength predict the maximum and minimum experimental AFC strengths, for each surface treatment, in the corroded and non- corroded conditions with accuracies of $95-104 \%$. This outcome shows the proposed model to predict the AFC strength considering surface treatments and corrosion is simple and accurate, and it should be used for design considerations. 
Table 5. Model accuracy on predicting the maximum and minimum experimental AFC strengths for four different surface treatments in the corroded and non-corroded conditions

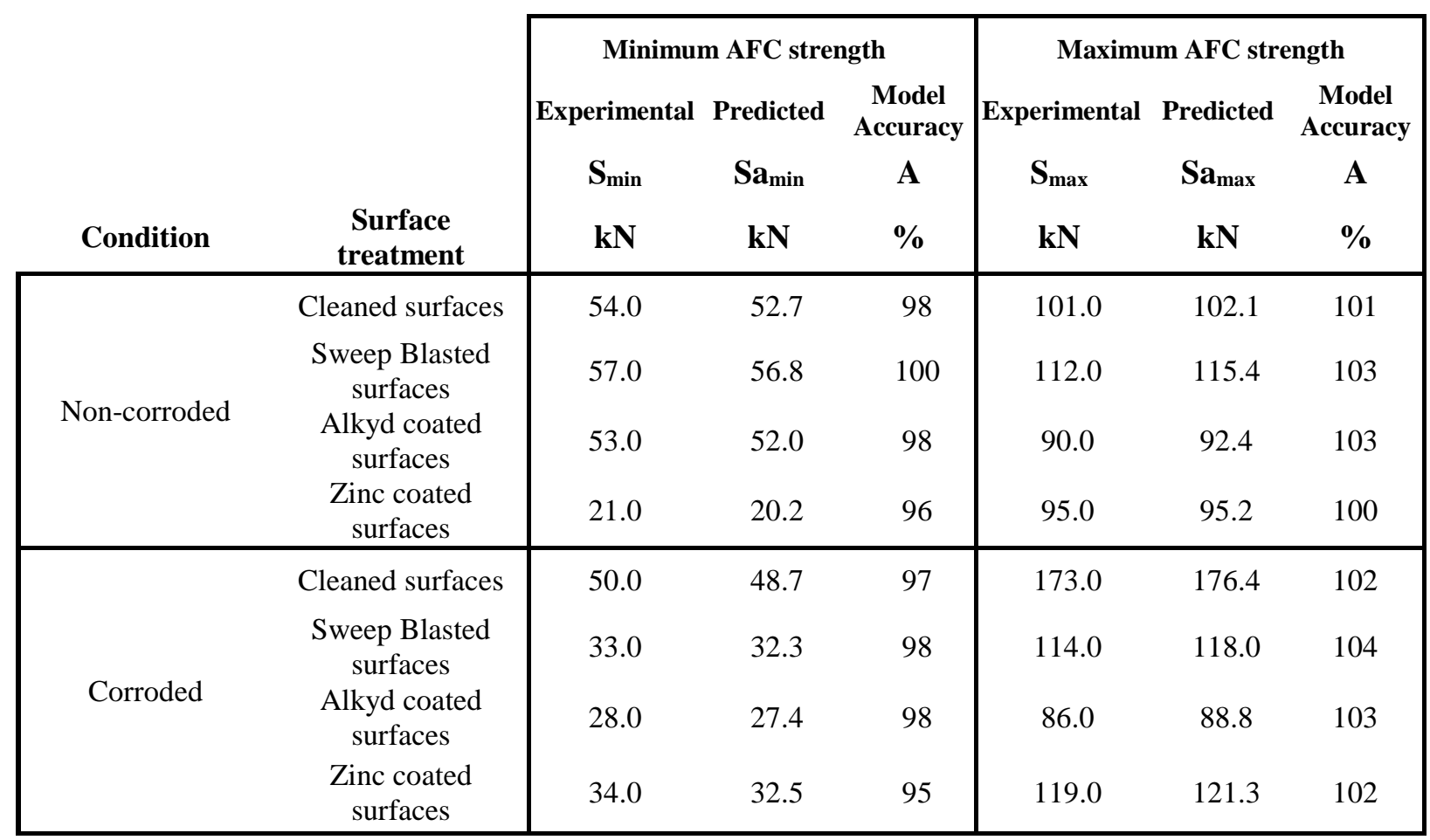




\section{CONCLUSIONS}

This paper describes the effects of surface treatment and corrosion on the hysteretic behaviour of AFCs with Bisalloy 500 shims. It was shown that:

i. AFCs developed general, crevice, and filiform corrosion. AFCs with cleaned and sweep blasted surfaces developed general corrosion on the external surfaces and crevice corrosion with the same appearance of general corrosion on the internal surfaces. AFCs with alkyd coated and zinc coated surfaces developed general corrosion on the external surfaces and filiform corrosion on the internal surfaces.

ii. In AFCs with cleaned surfaces the corrosion rate increased almost linearly and the mass loss increased parabolically with corrosive cycles. In AFCs with sweep blasted, alkyd coated, and zinc coated surfaces, the corrosion rate and mass loss are activated after certain number of cycles, and then the corrosion rate increased almost linearly and the mass loss increased parabolically with corrosive cycles. The most effective surface treatment to delay the corrosion attack is zinc coated surfaces.

iii. Hysteresis loop shape does not change with surface treatment. In AFCs with sweep blasted surfaces the hysteresis loop stability decreased and the average AFC strength increased. In AFCs with alkyd coated and zinc coated surfaces, the stability of the hysteresis loop did not decrease, and the average AFC strength reduced.

iv. Hysteresis loop shape does not change with corrosion except for the increased AFC strength at the initial sliding cycles. However, the hysteresis loop stability decreased 
slightly. Regardless of the surface treatment, as a result of corrosion, AFC strength increased significantly in the initial sliding cycles, and after the initial sliding cycles AFC strength decreased to an almost constant value approaching the AFC strength developed in the non-corroded condition.

v. The effective friction coefficient changed with surface treatment and corrosion. The effective friction coefficient increased for AFC with sweep blasted surfaces, and reduced for AFCs with alkyd coated and zinc coated surfaces. The greatest reductions in effective friction coefficient occurred for AFCs with zinc coated surfaces. Regardless of the surface treatment, due to corrosion, the effective friction coefficient increased significantly at the initial sliding cycles, and after the initial sliding cycles, it decreased to a value approaching the value in the non-corroded condition.

vi. The average AFC strength in the non-corroded condition for different surface treatments is expressed as function of the average effective friction coefficient and the total bolt proof load on the AFC. The maximum and minimum likely AFC strengths in the corroded and non-corroded conditions for different surface treatments can be assessed as the average AFC strength in the non-corroded condition factored by overstrength and understrength factors. The overstrength and understrength factors were experimentally determined, and range from 0.37 to 2.28 considering the increased AFC strength at the initial sliding cycles. 


\section{ACKNOWLEDGEMENTS}

The authors would like to acknowledge funding from MBIE Natural Hazards Research Platform (NHRP), and material donation from John Jones Steel Ltd., for undertaking this research. All opinions expressed remain those of the authors. 


\section{REFERENCES}

[1] Khoo HH, Clifton C, Butterworth J, MacRae G, Ferguson G (2011). Influence of steel shim hardness on the Sliding Hinge Joint Performance. Journal of Constructional Steel Research. Vol 72, May 2012, pp. 119 - 129. https://doi.org/10.1016/j.jcsr.2011.11.009

[2] Clifton GC (2005). Semi-Rigid Joints for Moments Resisting Steel Framed Seismic Resisting Systems. Published PhD Thesis, Department of Civil and Environmental Engineering. University of Auckland - New Zealand.

[3] Rodgers GW, Chase JG, Causse R, Chanchi Golondrino JC, MacRae GA (2017). Performance and Degradation of Sliding Steel Friction Connections: Impact of Velocity, Corrosion, Coating and Shim Material. Engineering Structures, Vol. 141, pp. 292-302. ISSN: 0141-0296. https://doi.org/10.1016/j.engstruct.2017.02.070

[4] MacRae GA, Clifton CG, MacKinven H, Mago N, Butterworth J, Pampanin S (2010). The Sliding Hinge Joint Moment Connection. Bulletin of the New Zealand Society for Earthquake Engineering. Vol 43, Issue 3, pp. 202-212.

[5] Borzouie J, Chase JG, MacRae GA, Rodgers GW (2015). Experimental Studies on Cyclic Performance of Column Base Weak Axis Aligned Asymmetric Friction Connection. Journal of Constructional and Steel Research (JCSR), Vol 112, pp. 252-262. https://doi.org/10.1016/j.jcsr.2015.05.007

[6] Borzouie J, Chase JG, MacRae GA, Rodgers GW, Clifton C (2016). Experimental Studies on Cyclic Performance of Column Base Strong Axis Aligned Asymmetric Friction Connections. ASCE J. Structural Engineering, Vol 142(1), 10-pages. https://doi.org/10.1061/(ASCE)ST.1943-541X.0001327 
[7] Xie, R., Chanchi, J., MacRae, G.A., and Clifton, C.G. (2018). Braced frame asymmetrical and symmetrical friction connection performance. Key Engineering Materials. Vol. 763, pp. 216 - 223. https://doi.org/10.4028/www.scientific.net/KEM.763.216

[8] Standards Australia/Standards New Zealand (2006). AS/NZS 4680. Hot-dip galvanized (zinc) coatings on fabricated ferrous articles. New Zealand.

[9] Standards Australia/Standards New Zealand (2014). AS/NZS 2312. Guide to the protection of structural steel against atmospheric corrosion by the use of protective coatings. New Zealand.

[10] ASTM International (2012). ASTM G31. Standard guide for laboratory immersion corrosion testing of metals. United States of America.

[11] Sarraf, E., R., Clifton, C., Mandeno, W. (2010). HERA Report R4-133: New Zealand Steelwork Corrosion and Coatings Guide. New Zealand Heavy Engineering Research Association. Manukau City - New Zealand.

[12] Khoo HH, Clifton GC, MacRae GA, Zhou H, Ramhormozian S (2014). Proposed design models for the asymmetric friction connection. Earthquake and Structural Dynamics Journal. Vol 44, Issue 8, pp. 1309-1324. https://doi.org/10.1002/eqe.2520

[13] Rodgers GW, Mesnil O, Chanchi Golondrino JC, MacRae GA, Chase JG (2014). Generalised nonlinear modeling of unstable stick-slip force reduction effects in friction energy dissipation devices. NZSEE Bulletin, Vol 47(3), pp. 217-223.

[14] Buchheit RG (2012). Corrosion resistant coatings and paints. In: Kuts, M. (editor). Handbook of Environmental Degradation of Materials, $2^{\text {nd }}$ edition. Elsevier, pp. 539 568. https://doi.org/10.1016/B978-1-4377-3455-3.00018-3 